\title{
Coagulation and fibrinolysis related cytokine imbalance in preeclampsia: the role of placental trophoblasts
}

\author{
Yin-Cheng Teng ${ }^{1}$, Qi-De Linn,*, Jian-Hua Lin², \\ Chuan-Wei Ding ${ }^{2}$ and Ye Zuo ${ }^{2}$ \\ ${ }^{1}$ Department of Obstetrics and Gynecology, Shanghai \\ Sixth People's Hospital, Shanghai Jiaotong University, \\ China \\ 2 Department of Obstetrics and Gynecology, Renji \\ Hospital, Shanghai Jiaotong University, School of \\ Medicine, Shanghai, China
}

\begin{abstract} preeclamptic and normal pregnancies. (TFPI), and TF. bility in patients with preeclampsia.

\footnotetext{
*Corresponding author:

Qi-De Lin, MD

Department of Obstetrics and Gynecology

Renji Hospital

Shanghai Jiaotong University

School of Medicine

145 Shandong Mid Road

Shanghai 200001

China

Tel: $+86-021-53070702$

Fax: +86-21-63730455

E-mail: shlinqide@sohu.com
}

Objective: Cytokine imbalance might have a pivotal role in hypercoagulability seen in preeclampsia. Our objective was to determine the relationship of blood coagulation related factors in placental tissue and peripheral blood in

Methods: We compared mRNA and protein levels of tissue-type plasminogen activator (t-PA), plasminogen activator inhibitor-1 (PAl-1), and tissue factor (TF) in the placenta of normal and preeclamptic pregnancies. Placental and peripheral blood t-PA and PAl-1 levels were examined. Trophoblasts were used to study the effects of hypoxia, hypoxia-reperfusion, and inflammatory cytokines on t-PA, PAl-1, tissue factor pathway inhibitor

Results: PAl-1 and TF mRNA and protein levels were higher in placental tissue of preeclamptic pregnancies and in the peripheral blood of patients with preeclampsia. mRNA and protein secretion of TF, TFPI, PAI-1, but not t-PA, was increased in trophoblast cell culture under hypoxia and hypoxia-reoxygenation. Cell cultures with high levels of tumor necrosis factor-alpha (TNF- $\alpha$ ) exhibited increased expression and secretion of TF and PAI1, decreased TFPI, and no significant change of t-PA.

Conclusions: Imbalanced synthesis of t-PA, PAI-1, TFPI, and TF in trophoblasts may contribute to hypercoagula-
Keywords: Cytokines; hypercoagulability; preeclampsia.

\section{Introduction}

Individuals with preeclampsia and eclampsia frequently exhibit a hypercoagulability state that includes intravascular coagulation, microthrombosis, and impaired uteroplacental circulation [16]. This hypercoagulable state significantly increases the incidence of complications and worsens the prognosis for mother and baby [16]. Thus far, the mechanism of hypercoagulability is not clear. Recent studies indicate that during normal pregnancy trophoblasts synthesize and secrete large amounts of cytokines, some of which have important regulatory roles in the placental and systemic coagulation and fibrinolytic systems. These cytokines often exist as pairs, i.e., as activators and inhibitors, and the delicate balance between them is important for the maintenance of normal placental blood flow and peripheral blood clotting [18]. For example, trophoblasts secret tissue-type plasminogen activator (t-PA) and urokinase-type plasminogen activator (u-PA). t-PA and u-PA modify inactive plasminogen and change it to active plasmin with extensive proteinase potential [3]. In order to maintain coagulation and balance of the fibrinolytic system, trophoblasts also secrete plasminogen activator inhibitors (PAls) of the serine protease inhibitor family that inhibit the activities of t-PA and u-PA. Over-expression of PAI-1 can inhibit fibrin degradation, thus leading to fibrin deposition around villi and impairment of nutrient exchange in the placenta [9]. Additionally, trophoblasts can express tissue factors (TFs). The interaction between TFs and factor VIla can initialize the external coagulation pathway. Trophoblasts also express tissue factor pathway inhibitor (TFPI), which inhibits the activity of TFs.

It has been shown that placental spiral arteries have incomplete recasting in patients with preeclampsia, and the blood flow in the intervillus space fluctuates. Doppler ultrasound studies have shown that the fluctuations of blood flow in the uterine arteries of patients with preeclampsia were significantly higher than in normal pregnancies [16]. Based on this, Burton et al. claimed that placental ischemia and hypoxia were not sustained and that hypoxia-reperfusion injury instead of stable chronic hypoxia might be the primary cause of tissue damage [6]. Under hypoxia and hypoxia-reperfusion conditions, the synthesis and release of tissue necrosis factor (TNF)- $\alpha$ in placental tissue by villi mesenchymal cells and mac- 
rophages increased significantly [25]. Clinical studies have confirmed that TNF- $\alpha$ levels are 2-3 times higher in patients with preeclampsia than in normal pregnancy $[4,18]$.

In this study, we compared mRNA and protein levels of t-PA, PAI, and TF in the placental tissue of normal and preeclamptic pregnancies. The relationship between placental and peripheral blood t-PA and PAl levels was also studied as well as the effects of hypoxia, hypoxia-reperfusion, and inflammatory cytokines on t-PA, PAI, TPPI, and TF expression.

\section{Materials and methods}

\section{Subjects and cell sources}

Forty women who delivered at the obstetric department of Renji hospital from March 2004 to December 2006 were studied; 20 had severe preeclampsia and 20 had normal pregnancies. Preeclampsia was diagnosed according to the criteria of the International Society for the Study of Hypertension [1]. Severe preeclampsia was defined as a sustained blood pressure $\geq 160$ / $110 \mathrm{~mm} \mathrm{Hg}$, proteinuria $\geq 5 \mathrm{~g} / 24 \mathrm{~h}$, and multi-organ involvement, i.e., renal, liver, cardiac, and/or brain damage [1] Hypercoagulability was confirmed by a prothrombin time (PT) shortened $>3 \mathrm{~s}$ compared to control, serum d-dimer $>0.5$ $\mathrm{mg} / \mathrm{L}$, and positive serum fibrin degradation products (FDPs). Patients had no history of primary hypertension, diabetes, chronic nephritis or other renal disease, blood dyscrasias, clotting disorders, or previous eclampsia or preeclampsia.

Trophoblast cells were acquired from the family planning clinic at our hospital from May 2005 to December 2005 from 10 women at 7- to 9-weeks' gestation who underwent elective termination of pregnancy. Patients were 22-33 years old, without high blood pressure, heart disease, chronic glomerulonephritis, other medical conditions, or history of eclampsia or preeclampsia. Ultrasound was used to confirm gestational age before termination. Specimens were pooled prior to use in subsequent studies.

\section{Specimen collection and preservation}

Before cesarean or vaginal delivery, $4.5 \mathrm{~mL}$ maternal venous blood was collected into tubes containing $0.5 \mathrm{~mL}$ EDTA. Samples were centrifuged at $2000 \mathrm{rpm}$ for $10 \mathrm{~min}$, and then $1 \mathrm{~mL}$ plasma was extracted and stored at $-30^{\circ} \mathrm{C}$. After delivery of the placenta, blood and tissue samples were immediately collected under aseptic conditions from the center of the maternal side of the placenta, opposite to the site of umbilical cord attachment. The depth of sampling was the outer $1 / 3$ of the placenta thickness. All samples were collected from this area to achieve consistent sampling. The collection procedure did not exclude deciduas; thus, some decidual tissue may have been mixed in the samples. Tissue blocks sized $0.5 \times 0.5 \times 0.5 \mathrm{~cm}^{3}$ were washed with phosphate buffered saline (PBS) and then placed in liquid nitrogen for RNA and protein extraction.

\section{Isolation and culture of trophoblasts}

The methods of isolation and culture of trophoblasts were described by Aharon [2]. In short, villi were rinsed with PBS and cut into 1-2 $\mathrm{mm}^{3}$ pieces, digested by $0.125 \%$ trypsin for $30 \mathrm{~min}$, and then by $25 \mathrm{U} / \mathrm{mL}$ clarity II collagenase for $15 \mathrm{~min}$. Samples were then filtered with a $100 \mu \mathrm{m}$ double-layered nylon net, and centrifuged at $2000 \mathrm{rpm}$ for $20 \mathrm{~min}$. The supernatant was discarded and the cells were suspended and allowed to settle in a $1.25-2.5 \%$ bovine serum albumin (BSA) density gradient for $1 \mathrm{~h}$. The trophoblasts were then collected and suspended in Dulbecco's modified Eagle media (DMEM) +F12 culture medium and cell supernatant liquid was prepared to make the concentration of trophoblasts $2 \times 10^{6} / \mathrm{mL}$. Cells were cultured on pre-treated plates (24 h prior to culture, plates were covered with matrix gel) at $37^{\circ} \mathrm{C}$ in a $5 \% \mathrm{CO}_{2}$ incubator overnight. After $24 \mathrm{~h}$ the cultures were examined using an inverted microscope and the adhesions between the cells and the wall were noted to be good. The medium was changed and the culture continued to $72 \mathrm{~h}$ at which point cell growth, division, and syncytium phenomenon in merged cells were seen. Cells were then divided into groups for study.

\section{Experimental grouping of the primary trophoblasts}

Placental trophoblasts were inoculated onto 24-well plates, each well containing $1 \times 10^{6}$ cells. Three wells were used for each group. The groups were: 1) control, cultured in a $5 \% \mathrm{CO}_{2}$ incubator at $37^{\circ} \mathrm{C}$ for $24 \mathrm{~h}$; 2) IL-10 group, $10 \mathrm{ng} / \mathrm{mL}$ IL-10 added, cultured in a $5 \% \mathrm{CO}_{2}$ incubator at $37^{\circ} \mathrm{C}$ for $24 \mathrm{~h}$; 3) IL-12 group, $20 \mathrm{ng} / \mathrm{mL} \mathrm{IL}-12$ added, cultured in a $5 \% \mathrm{CO}_{2}$ incubator at $37^{\circ} \mathrm{C}$ for $24 \mathrm{~h}$; 4) TNF- $\alpha$ group, $20 \mathrm{ng} / \mathrm{mL}$ TNF- $\alpha$ added, cultured in $5 \% \mathrm{CO}_{2}$ incubator at $37^{\circ} \mathrm{C}$ for $\left.24 \mathrm{~h} ; 5\right)$ hypoxia group, cultured in a $2 \%$ oxygen, $5 \% \mathrm{CO}_{2}, 93 \% \mathrm{~N} 2$ gas incubator at $37^{\circ} \mathrm{C}$, for $24 \mathrm{~h} ; 6)$ hypoxia-reoxygenation group, cultured in a $2 \%$ oxygen, $5 \% \mathrm{CO}_{2}, 93 \% \mathrm{~N} 2$ gas incubator at 37 , for $24 \mathrm{~h}$, then after medium change, cultured in a $5 \% \mathrm{CO}_{2}$ incubator at $37^{\circ} \mathrm{C}$ for $24 \mathrm{~h}$.

The supernatant was collected from the culture, and after centrifugation, $0.5 \mathrm{~mL}$ was stored $-80^{\circ} \mathrm{C}$ for later testing. The cultured medium in the culture wells was emptied and $0.5 \mathrm{~mL}$ TRIzol reagent was added into the wells to destroy the cells. The cell lysate in the wells was collected and preserved in liquid nitrogen.

\section{ELISA measurement of TF, TFPI-1, TFPI-2, t-PA, and PAI-1 in serum and cell culture supernatant}

TF, TFPI-1, and TFPI-2 quantification was performed with ELISA kits manufactured by ASSAYPRO LLC (St. Charles, MO, USA). t-PA and PAl-1 quantification was performed with ELISA kits manufactured by Sun Biotechnology Ltd. (Shanghai). Methods and steps described in the package insert of the respective kits were strictly followed.

\section{Quantitative RT-PCR assay of TF, TFPI-1, TFPI-2, t-PA, PAI-1, and glyceraldehyde-3-phosphate dehydrogenase (GAPDH) mRNA expression in placental tissue}

Total RNA was extracted according to the TRIzol Reagent Kit manual (Invitrogen, Carlsbad, USA). The expression level of the 
GAPDH gene was used for normalization. The sequences of the primers for the genes were as follows:

PAI-1: PAI-forward, CAGACCAAGAGCCTCTCCAC; PAl-reverse, ATCACTTGGCCCATGAAAAG.

t-PA: t-PA-forward, CCATGCCCGATTCAGAAGAG; t-PA-reverse, GGCCCTGGTATCTATTTCA.

TF: TF-forward, CCGAACAGTTAACCGGAAGA; TF-reverse, TCAGTGGGGAGTTCTCCTTC.

TFPI-2: TFPI-2-forward, GGAGCCAACAGGAAATAACG;

TFPI-2-reverse, CCGGCAAACTTTGGGAACTT.

TFPI-1: TFPI-1-forward, GCCACCACTGAAACTTATGC; TFPI-1-reverse, TCTCAAATTGTTCATATTGCCCA.

GAPDH: GAPDH-forward,

GAAGGTGAAGGTCGGAGTC; GAPDH-reverse, GAAGATGGTGATGGGATTTC.

Quantitative RT-PCR was conducted according to the methods recommended by Takara (Japan) and UVItec (Cambridge, UK) with GAPDH included for normalization. In short, Takara premix Ex Tag Real-time PCR system was used. A $5 \mu \mathrm{L}$ sample of PCR products was mixed with $1 \mu \mathrm{L}$ loading buffer containing $0.5 \mu \mathrm{g} / \mathrm{mL}$ ethidium bromide (EB) (also provided by the kit) then loaded on $1.5 \%$ agarose gel for electrophoresis. The UVIpro gel image analysis system (UVItec) was used to observe the sample and take pictures. UVI Band and SDS2.1 software (supplied with the UVIpro system) was used to analyze the CT value of each sample. (When templates were amplified to a certain copy number, the exponential amplification of PCR reaction became observable. CT value is the reaction circle numbers required to observe the exponential phase of the PCR reaction.) A standardized $-\Delta \Delta C T$ value was calculated (a larger value indicates a greater number of initial copies). $-\Delta \Delta C T$ value $=2$ minus (CT value of the target gene minus the CT value of GAPDH gene from the same sample).

\section{Western blot analysis of t-PA and PAI-1 protein levels in placental tissue}

Protein samples were extracted and concentrated following the directions in the TRIzol manual. Protein quantification was done using a Biophotometer UV spectrophotometer (Eppendorf, Germany). The protein samples were electrophoresed at $100 \mu \mathrm{g}$ total protein per lane for each sample, and then transferred onto nitrocellulose membrane. 10\% skim milk (diluted by Tris-buffered saline containing Tween-20 [TBST]) was used for blocking the membrane at room temperature for $1 \mathrm{~h}$. After overnight incubation at $4^{\circ} \mathrm{C}$ with rat anti-human-t-PA antibodies, or rat antihuman-PAl-1 antibody (American Diagnostic Inc., Santa Cruz, CA, USA), the membrane was rinsed twice with PBS then incubated with rabbit anti-rat antibody (Amersham, Piscataway, NJ, USA) at a dilution of $1: 100$ at $37^{\circ} \mathrm{C}$ for $1 \mathrm{~h}$. Bands on the membrane were visualized on X-ray films by the Enhanced Chemical Fluorescence assay (ECF) (Amersham) following the manufacturer's directions. X-ray film scanning and analysis was performed with Gel-Pro Analyzer software (Amersham). The relative content of the target protein was the ratio of the intensity of the target protein bands to that of the GAPDH bands.

\section{Statistical analysis}

The SAS statistical package (SAS Institute Inc., Cary, NC, USA) was used for statistical analysis. Measurements were shown as arithmetic mean \pm standard deviation (mean $\pm S D$ ); a group $t$-test was performed. $\mathrm{P}<0.05$ indicated significance. Linear regression was conducted to test the association; $P<0.05$ indicates significant association.

\section{Results}

The mRNA level of TF and PAI-1 genes in placental tissue in preeclampsia was higher than in a normal pregnancy without significant difference between the levels of t-PA mRNA (Table 1). PAl-1 protein level was higher in placental tissue in preeclampsia than in normal pregnancy without significant difference in the protein level of t-PA (Table 2).

Peripheral blood levels of t-PA in patients with preeclampsia were significantly lower compared to those in women with a normal pregnancy. Conversely, peripheral blood levels of PAl-1 in patients with preeclampsia were significantly increased compared to those in women with a normal pregnancy (Table 3). No significant correlation between peripheral PAI-1 levels and placental PAI-1 in either normal or preeclamptic patients was found. In preeclamptic patients, however, peripheral blood t-PA levels were positively correlated with placental t-PA protein levels $(P<0.05$, Table 4$)$.

TF, TFPI-1, TFPI-2, and PAI-1 gene expression in the hypoxia and hypoxia-reoxygenation groups were significantly higher than in controls. Additionally, TFPI-1 gene expression in the hypoxia-reoxygenation group was significantly higher than in the hypoxia group $(P<0.01)$. With TNF- $\alpha$ stimulation, TF, TFPI-2, and PAl-1 gene expression in trophoblasts increased greatly and were significantly different from that of the control group, whereas TFPI-1 gene expression decreased and was significantly

Table 1 Comparison of t-PA, PAl-1, and TF mRNA levels in placental tissue from normal and preeclamptic pregnancies.

\begin{tabular}{lll}
\hline & $\begin{array}{l}\text { Normal pregnancy } \\
(\mathrm{n}=20)\end{array}$ & $\begin{array}{l}\text { Preeclampsia } \\
(\mathrm{n}=20)\end{array}$ \\
\hline t-PA & $2.16 \pm 1.22$ & $1.70 \pm 0.88$ \\
PAl-1 & $59.52 \pm 47.29$ & $66.15 \pm 27.70^{a}$ \\
TF & $10.32 \pm 3.86$ & $16.64 \pm 6.49^{a}$ \\
\hline
\end{tabular}

Results are shown as mean \pm SD of $-\Delta \Delta$ CT value.

ap $<0.05$.

Table 2 Comparison of t-PA, PAl, and TF protein levels in placental tissue from normal and preeclamptic pregnancies.

\begin{tabular}{lll}
\hline & $\begin{array}{l}\text { Normal pregnancy } \\
(\mathrm{n}=20)\end{array}$ & $\begin{array}{l}\text { Preeclampsia } \\
(\mathrm{n}=20)\end{array}$ \\
\hline t-PA & $0.13 \pm 0.06$ & $0.11 \pm 0.06$ \\
PAI-1 & $0.17 \pm 0.05$ & $0.22 \pm 0.06^{\mathrm{a}}$ \\
TF & $0.44 \pm 0.13$ & $0.66 \pm 0.13^{\mathrm{a}}$ \\
\hline
\end{tabular}

Results are shown as mean \pm SD of relative unit. aP $<0.05$. 
Table 3 Comparison of t-PA, PAI, and TF blood levels in normal and preeclamptic pregnancies.

\begin{tabular}{lll}
\hline & $\begin{array}{l}\text { Normal pregnancy } \\
(\mathrm{n}=20)\end{array}$ & $\begin{array}{l}\text { Preeclampsia } \\
(\mathrm{n}=20)\end{array}$ \\
\hline $\mathrm{t}-\mathrm{PA}(\mathrm{ng} / \mathrm{mL})$ & $67.12 \pm 18.91$ & $42.03 \pm 16.08^{\mathrm{a}}$ \\
$\mathrm{PAl}-1(\mathrm{ng} / \mathrm{mL})$ & $63.15 \pm 8.88$ & $81.37 \pm 4.87^{\mathrm{a}}$ \\
$\mathrm{TF}(\mathrm{pg} / \mathrm{mL})$ & $30.84 \pm 9.04$ & $53.02 \pm 8.64^{\mathrm{a}}$ \\
\hline
\end{tabular}

Results are shown as mean \pm SD.

aP $<0.01$.

Table 4 Correlation between t-PA, PAl-1, and TF protein levels in peripheral blood and placental tissue in normal and preeclamptic pregnancies.

\begin{tabular}{llcc}
\hline & & $\begin{array}{l}\text { Correlation } \\
\text { coefficient }(r)\end{array}$ & P-value \\
\hline t-PA & Normal pregnancy & -0.1176 & $>0.05$ \\
& Preeclampsia & 0.4833 & $<0.05$ \\
PAl-1 & Normal pregnancy & -0.0419 & $>0.05$ \\
& Preeclampsia & 0.1962 & $>0.05$ \\
TF & Normal pregnancy & 0.2794 & $>0.05$ \\
& Preeclampsia & 0.9471 & $<0.01$ \\
\hline
\end{tabular}

lower than in the control group. The gene expression of PAI-1 was significantly higher than in the control group and the hypoxia group. IL-10 at $20 \mathrm{ng} / \mathrm{mL}$ did not significantly affect gene expression but IL-12 at $20 \mathrm{ng} / \mathrm{mL}$ significantly increased the mRNA expression of TFPI-1 compared to the control group. No significant effects on other cytokines examined were noted. Finally, the expression of t-PA mRNA in trophoblasts was very low, and was not affected by hypoxia or inflammatory factors (Table 5).

Testing the supernatant of cell culture showed that in hypoxia and hypoxia-reoxygenation culture conditions, the concentrations of TF, TFPI, and PAI-1 increased significantly compared to the control group $(P<0.01)$. t-PA level was not significantly different from that of the control group under the hypoxia condition, but it was significantly lower under the hypoxia-reoxygenation condition. TNF- $\alpha$ at $20 \mathrm{ng} / \mathrm{mL}$ significantly increased the secretion of TF and PAI-1 and decreased the secretion of TFPI compared to the control group $(P<0.01)$, but had no significant effect on the secretion of t-PA. IL-10 and IL-12 at $20 \mathrm{ng} / \mathrm{mL}$ did not have any significant effect on the secretion of coagulation related factors (Table 6).

\section{Discussion}

Results of this study show that TF and PAl-1 gene expression and protein levels in the placental tissue of preeclamptic pregnancies are higher than those in normal pregnancy. Likewise, TF and PAl-1 concentrations in the peripheral blood of patients with preeclampsia are sig-

Table 5 Effects of hypoxia and cytokines on the gene expression of the blood coagulation related factors in the trophoblasts.

\begin{tabular}{llllll}
\hline Group & TF & TFPI-1 & TFPI-2 & t-PA & PAI-1 \\
\hline Control & $0.31 \pm 0.06$ & $91.68 \pm 11.48$ & $8.24 \pm 0.81$ & $0.29 \pm 0.03$ & $11.26 \pm 0.58$ \\
Hypoxia & $0.60 \pm 0.02^{\mathrm{a}}$ & $138.39 \pm 39.08^{\mathrm{a}, \mathrm{b}}$ & $15.60 \pm 3.64^{\mathrm{c}}$ & $0.31 \pm 0.06$ & $14.65 \pm 1.89^{\mathrm{b}, \mathrm{c}}$ \\
Hypoxia-reoxygenation & $0.69 \pm 0.29^{\mathrm{c}}$ & $142.54 \pm 26.21^{\mathrm{c}, \mathrm{d}}$ & $12.50 \pm 1.69^{\mathrm{c}}$ & $0.24 \pm 0.07$ & $16.49 \pm 2.55^{\mathrm{c}}$ \\
IL-10 & $0.29 \pm 0.07$ & $98.13 \pm 12.95$ & $7.86 \pm 1.31$ & $0.27 \pm 0.07$ & $10.99 \pm 2.42$ \\
IL-12 & $0.33 \pm 0.03$ & $106.17 \pm 36.18^{\mathrm{a}}$ & $8.36 \pm 0.92$ & $0.29 \pm 0.07$ & $9.26 \pm 2.37$ \\
TNF- $\alpha$ & $0.72 \pm 0.12^{\mathrm{c}}$ & $62.89 \pm 31.29^{\mathrm{c}}$ & $13.21 \pm 1.30^{\mathrm{c}}$ & $0.25 \pm 0.08$ & $43.73 \pm 3.22^{\mathrm{c}}$ \\
\hline
\end{tabular}

Results are shown as mean \pm SD of $-\Delta \Delta C T$ value.

aStatistically significant compared with the control group $(P<0.05)$.

bStatistically significant between hypoxia and TNF- $\alpha$ groups $(\mathrm{P}<0.01)$.

${ }^{\mathrm{c} P}<0.01$.

dStatistically significant between hypoxia and hypoxia-reoxygenation groups $(P<0.01)$.

Table 6 Effects of hypoxia and cytokines on the secretion of the blood coagulation related factors in the trophoblasts.

\begin{tabular}{|c|c|c|c|c|}
\hline Groups & $\begin{array}{l}\mathrm{TF}(\mathrm{pg} / \mathrm{mL}) \\
\text { Mean } \pm \mathrm{SD}\end{array}$ & $\begin{array}{l}\text { TFPI }(\mathrm{ng} / \mathrm{mL}) \\
\text { Mean } \pm \mathrm{SD}\end{array}$ & $\begin{array}{l}\mathrm{t}-\mathrm{PA}(\mathrm{ng} / \mathrm{mL}) \\
\text { Mean } \pm \mathrm{SD}\end{array}$ & $\begin{array}{l}\text { PAl-1 }(\mathrm{ng} / \mathrm{mL}) \\
\text { Mean } \pm \text { SD }\end{array}$ \\
\hline Control & $126.72 \pm 5.60$ & $3.74 \pm 0.32$ & $4.32 \pm 1.01$ & $40.31 \pm 7.18$ \\
\hline Hypoxia & $138.71 \pm 4.79^{a}$ & $4.80 \pm 0.49^{a}$ & $3.91 \pm 0.78$ & $87.62 \pm 9.97^{a}$ \\
\hline Hypoxia-reoxygenation & $148.22 \pm 6.74^{\mathrm{a}, \mathrm{b}}$ & $5.30 \pm 0.56^{a}$ & $2.34 \pm 1.68^{a}$ & $100.70 \pm 7.17^{\mathrm{a}, \mathrm{b}}$ \\
\hline IL-10 & $130.79 \pm 4.34$ & $3.98 \pm 0.82$ & $4.34 \pm 1.26$ & $33.89 \pm 7.58$ \\
\hline IL-12 & $128.83 \pm 7.09$ & $4.12 \pm 0.76$ & $4.00 \pm 2.06$ & $35.75 \pm 6.13$ \\
\hline TNF- $\alpha$ & $142.29 \pm 5.58^{\mathrm{a}}$ & $3.19 \pm 0.44^{a}$ & $3.52 \pm 0.79$ & $63.68 \pm 7.24^{a}$ \\
\hline
\end{tabular}

Results are shown as mean \pm SD.

aStatistically significant compared with the control group $(\mathrm{P}<0.01)$.

bStatistically significant between the hypoxia and hypoxia-reoxygenation group $(P<0.01)$. 
nificantly increased compared to those in a normal pregnancy. These results suggest that high expression of PAI-1 and TF in the placenta and the secretion of these cytokines into the blood by placental tissue might be associated with the hypercoagulable state seen in preeclampsia. Correlation analysis showed that PAl-1 levels in peripheral blood in both normal and preeclamptic pregnancies were not significantly correlated with local placental PAI-1 levels. This suggests that the cause of increased peripheral PAl-1 in preeclampsia is multifactorial. Additionally, vascular endothelial cells, neutrophils, and macrophage activation may also play a role in increasing PIA-1 levels [17].

The results of this study also showed that patients with preeclampsia had significantly decreased t-PA concentrations as compared with normal pregnancy. The physiological effects of t-PA are to decrease the activity of the fibrinolytic system, thus causing a relative increase of coagulation activity. The data indicate that t-PA gene expression and protein levels in the placentas of patients with preeclampsia are not significantly different from those in normal pregnancy. A previous study showed that placental area and total number of trophoblast cells in preeclampsia was less than in normal pregnancy [14]. Therefore, it was speculated that the overall t-PA secretion from the placenta in preeclamptic patients must be less than in normal pregnancy, potentially contributing to the lower peripheral t-PA level in preeclamptic patients. Gao et al. [10] found that patients with preeclampsia had increased plasma PAl-1 levels, and there existed an imbalance between the plasminogen activators (t-PA, $\mathrm{u}-\mathrm{PA}$ ) and inhibitor (PAI-1). They concluded that this imbalance might be one of the reasons for the onset of preeclampsia. Our results support this theory, and also suggest that the imbalance of expression levels of the plasminogen activators and inhibitors in placental tissue may be a contributing factor to their imbalance in patients with preeclampsia.

Studies have demonstrated that t-PA levels vary with gestational age, but the increase of t-PA in late pregnancy is insignificant $[5,22]$. It has also been demonstrated that the t-PA production of trophoblast is unaffected by estrogen (E2) and progestogens (P) [24]. These observations are consistent with the findings in the present study, which suggest the t-PA expression in trophoblasts is relatively consistent and independent of the other factors studied.

Solovey et al. [23] reported that the hypoxia-reperfusion injury could cause significantly increased expression of TF in vascular endothelial cells, but no reports are available on the effects of hypoxia-reperfusion injury on the expressions of blood coagulation related cytokines in trophoblasts. This study found that under hypoxic conditions, trophoblast cell TF, TFPI, TFPI-2, and PAI-1 gene expression and protein secretion were significantly increased, whereas t-PA caused no significant changes.
After $24 \mathrm{~h}$ hypoxia followed by $24 \mathrm{~h}$ reoxygenation, the gene expression of TF, TFPI, and PAI-1 was not significantly different than that of the hypoxia group; however, the secretion of TF and PAI-1 was further increased. Additionally, t-PA gene expression and associated protein level significantly decreased. TFPI-2 mRNA expression declined slightly in hypoxia-reoxygenation conditions. Increased PAl-1 expression can inhibit t-PA activation of plasminogen to plasmin leading to inhibition of fibrin degradation and deposition of fibrin deposits in placental tissue.

Elevated levels of TNF- $\alpha$ in the peripheral blood of patients with preeclampsia can activate vascular endothelial cells and monocytes, enabling their synthesis and release of tissue factors, including PAI-1 [13, 19, 20]. This study found that trophoblasts might also participate in the process. TF and PAl-1 gene expression was significantly increased in trophoblasts by TNF- $\alpha$ at 20 $\mathrm{ng} / \mathrm{mL}$, and the degree of their increase was higher than under hypoxic conditions. Kwaan et al. [15] found that stimulated by TNF- $\alpha$, TF gene expression and protein synthesis in cultured trophoblasts of patients with preeclampsia were significantly higher than in a normal pregnancy. They believe this phenomenon cannot be explained by TNF- $\alpha$ induced cell apoptosis, and speculate that TF gene expression in trophoblasts of patients with preeclampsia has a unique genetic sensitivity to TNF- $\alpha$ stimulation.

The tissue factor pathway (extrinsic pathway) is the primary process responsible for intravascular blood coagulation in pregnancy. TF is the primary trigger whereas TFPI is the major inhibitor. TFPI-1 binds with TF and factor VIla to form a triplex and in turn inhibits the activation of factor $X$ to block the formation of thrombin. TFPI- 1 can be produced by placenta syncytiotrophoblasts, Langhans cells, and endothelial cells [8]. Knock-out of TFPI causes abnormal embryonic development, which suggested that TFPI is equally important as TF in maintenance of a balanced coagulation state at the maternalfetal interface [11]. TFPI-2, first identified in placenta, inhibits amino acid degradation caused by multiple enzymes, including the TF-VIla complex. However, TFPI2 does not affect the activation of t-PA, u-PA, APC, and factor Xa [21]. TFPI-2 is produced by trophocytes and endothelial, epithelial, and smooth muscle cells. Because $60-90 \%$ of TFPI-2 is deposited in the extracellular matrix, TFPI-2 level in circulation is normally low [12]. However, in the late stage of pregnancy, a large amount TFPI-2 is synthesized by the placenta and its level in circulation increases significantly [7].

The contribution of other tissue/cell types to preeclampsia cannot be excluded by the data presented, which is a limitation of the study. However, studies have suggested that trophoblasts play an active role in t-PA and TF secretion in normal pregnancy, whereas endothelial cell function is not significantly altered $[3,20]$. This 
was the rationale leading us to focus on the trophoblast in the present study. Indeed, experimental data are needed to clarify the role of endothelial cells in preeclampsia, and this is a topic of future studies.

In summary, this study showed that the imbalanced synthesis and secretion of the blood coagulation and fibrinolysis related cytokines, including t-PA, PAI-1, TFPI, and TF in trophoblasts may promote hypercoagulability in patients with preeclampsia. The hypoxia-reperfusion injury, and subsequent high TNF- $\alpha$ in placental tissue might lead to imbalanced cytokine gene expression in trophoblasts. The present data suggest the role of trophoblasts in cytokine imbalance seen in peripheral blood. The significance and importance of their participation are to be further determined.

\section{References}

[1] ACOG Committee on Obstetric Practice. ACOG practice bulletin. Diagnosis and management of preeclampsia and eclampsia. Number 33, January 2002. American College of Obstetrics and Gynecologists. Int J Gynecol Obstet. 2002;77:67-75.

[2] Aharon A, Brenner B, Katz T, Miyagi Y, Lanir N. Tissue factor and tissue factor pathway inhibitor levels in trophoblast cells: implications for placental hemostasis. Thromb Haemost. 2004;92:776-86.

[3] Anteby EY, Greenfield C, Natanson-Yaron S, GoldmanWohl D, Hamani Y, Khudyak V, et al. Vascular endothelia growth factor, epidermal growth factor and fibroblast factor -4 and -10 stimulate trophoblast plasminogen activator system and metalloproteinase-9. Mol Hum Reprod. 2004;10:229-35.

[4] Bellart J, Gilabert R, Anglès A, Piera V, Miralles RM, Monasterio $\mathrm{J}$, et al. Tissue factor levels and high ratio of fibrinopeptide A:D-dimer as a measure of endothelial procoagulant disorder in pre-eclampsia. $\mathrm{Br} \mathrm{J}$ Obstet Gynaecol. 1999;106:594-7.

[5] Belo L, Santos-Silva A, Rumley A, Lowe G, Pereira-Leite L, Quintanilha A, et al. Elevated tissue plasminogen activator as a potential marker of endothelial dysfunction in preeclampsia: correlation with proteinuris. BIOG. 2002; 109:1250-5.

[6] Burton J, Mashiah R, Cohen-Sacher B, Hod M, Orvieto R, Ben-Rafael Z, et al. Effect of thrombophylaxis on uterine and fetal circulation in pregnant women with a history of pregnancy complications. Thromb Res. 2002;102:235-41.

[7] Bützow R, Virtanen I, Seppälä M, Närvänen O, Stenman UH, Ristimäki A, et al. Monoclonal antibodies reacting with placental protein 5: use in radioimmunoassay, Western blot analysis, and immunohistochemistry. J Lab Clin Med. 1988;111:249-56.

[8] Edstrom CS, Calhoun DA, Christensen RD. Expression of tissue factor pathway inhibitor in human fetal and placental tissues. Early Hum Dev. 2000;59:77-84.

[9] Feng Q, Liu K, Liu YX, Byrne S, Ockleford CD. Plasminogen activators and inhibitors are transcribed during early macaque implantation. Placenta. 2001;22:186-99.

[10] Gao M, Nakabayashi M, Sakura M, Takeda Y. The imbalance of plasminogen activators and inhibitor in preeclampsia. J Obstet Gynaecol Res. 1996;22:9-16.

[11] Huang ZF, Higuchi D, Lasky N, Broze GJ Jr. Tissue factor pathway inhibitor gene disruption produces intrauterine lethality in mice. Blood. 1997;90:944-51.

[12] lino M, Foster DC, Kisiel W. Quantification and characterization of human endothelial cell-derived tissue factor pathway inhibitor-2. Arterioscler Thromb Vasc Biol. 1998; 18:40-6.

[13] Isermann B, Sood R, Pawlinski R, Zogg M, Kalloway S, Degen $\mathrm{JL}$, et al. The thrombomodulin-protein $\mathrm{C}$ system is essential for the maintenance of pregnancy. Nat Med. 2003;9:331-7.

[14] Kadyrov M, Kingdom JC, Huppertz B. Divergent trophoblast invasion and apoptosis in placental bed spiral arteries from pregnancies complicated by maternal anemia and early onset preeclampsia/intrauterine growth restriction. Am J Obstet Gynecol. 2006;194:557-63.

[15] Kwaan HC, Wang J, Boggio L, Weiss I, Grobman WA. The thrombogenic effect of an inflammatory cytokine on trophoblasts from women with preeclampsia. Am J Obstet Gynecol. 2004;191:2142-7.

[16] Lanir N, Aharon A, Brenner B. Haemostastic mechanisms in human placenta. Best Pract Res Cl Ha. 2003;16:183-95.

[17] Lash GE, Otun HA, Innes BA, Kirkley M, De Oliveira L, Searle RF, et al. Interferon- $\gamma$ inhibits extravillous trophoblast cell invasion by a mechanism that involves both changes in apoptosis and protease levels. FASEB J. 2006;20:2512-8

[18] Many A, Schreiber L, Rosner S, Lessing JB, Eldor A, Kupferminc MJ. Pathologic features of the placenta in women with severe pregnancy complications and thrombophilia. Obstet Gynecol. 2001;98:1041-4.

[19] Mello G, Parretti E, Marozio L, Pizzi C, Lojacono A, Frusca $\mathrm{T}$, et al. Thrombophilia is significantly associated with severe preeclampsia. Hypertension. 2005;46:1270-4.

[20] Neale D, Caze R, Small M, Krikun G, Mor G. First trimester trophoblast exposed to the sera of women with preeclampsia have increased secretion of tissue factor. Am J Obstet Gynecol. 2005;193:S13.

[21] Petersen LC, Sprecher CA, Foster DC, Blumberg H, Hamamoto T, Kisiel W. Inhibitory properties of a novel human Kunitz-type protease inhibitor homologous to tissue factor pathway inhibitor. Biochemistry. 1996;35:26672

[22] Sartori MT, Serena A, Saggiorato G, Campei S, Faggian D, Pagnan $A$, et al. Variations in fibrinolytic parameters and inhibin-A in pregnancy: related hypertensive disorders. $J$ Thromb Haemost. 2008;6:352-8.

[23] Solovey A, Kollander R, Shet A, Milbauer LC, Choong S, Panoskaltsis-Mortari A, et al. Endothelial cell expression of tissue factor in sickle mice is augmented by hypoxia/ reoxygenation and inhibited by lovastatin. Blood. 2004; 104:840-6.

[24] Ueyama M, Kasatori N, Urayama T, Maemura T, Yao Y, Shiraishi T, et al. Quantitative evaluation of the influence of ovarian steroids on plasminogen activators and inhibitors in human endometrial cells and trophoblasts. Thromb Res. 2002;25:235-44.

[25] Wiwanitkit V. Correlation between plasminogen activator inhibitor-1 4G/5G polymorphism and preeclampsia: an appraisal. Arch Gynecol Obstet. 2006;273:322-4.

The authors stated that there are no conflicts of interest regarding the publication of this article.

Received April 15, 2008. Revised November 19, 2008. Accepted January 20, 2009. Previously published online March 17, 2009. 